\section{SUMMARY OF RESEARCH REPORT: FOREIGN \\ LANGUAGE TEACHING IN THE SOUTHERN PART OF THAILAND}

\section{Pratana Karnnawakul ${ }^{1}$}

This research report synthesizes the research data on foreign-language education and use in southern Thailand. The project was conducted by six different research groups working toward the same objectives, namely: to explore the current state of foreign-language education and use at all academic levels and to examine satisfaction, needs, and problems related to foreign-language use in the business sector in southern Thailand.

The sample under the project included those from the business sector (owners/staff head and staff workers) and from the academic arena (teachers and learners of foreign languages and administrators). The total number of the sample w as 875 . P urposive s ampling and simple random sampling methods were used at different stages of the sampling in an attempt to capture sample subjects for as many different foreign-languages and as many types of institution and business as possible.

The research data showed that eleven foreign-languages have been taught in southern Thailand: English, French, German, Spanish, Italian, Japanese, Korean, Mandarin, Malay, Arabic, and

\footnotetext{
${ }^{1}$ Ph.D., Assistant Professor, and Associate dean for Academic Affairs and International Relations of Prince of Songkla University, Pattani Campus.
}

Khmer. English was the only language taught at all levels of education and in all academic institutions. Malay and Arabic were taught at all levels yet restricted to Islamic private schools, Tadika for primary education, and certain institutions at the tertiary level.

Most foreign-language teachers were Thai, some of whom were not trained in the language they were assigned to teach. A great number of them used Thai as a medium of instruction and were most proficient at reading and least proficient at speaking and listening. Hence, the two least proficient skills were most in need of improvement. Almost all teachers in the sample reported the use of integrated skills in their teaching approach. Yet multiplechoice or written examinations were frequently employed as methods of assessment, leaving speaking and listening skills unassessed. Some teachers revealed that the scope of content in the curriculum was too broad to be covered within the limited sessions. Others still had difficulty in implementing the curriculum and providing activities suited to its objectives. The problems found most frequently among the teachers were excessive workload and the lack of opportunity to develop their own expertise. The problems relating to teaching were, on the one hand, huge class size and, on the other hand, learners' poor foreignlanguage background and their lack of learning enthusiasm, confidence, and courage to perform language tasks.

Learners were rarely exposed to any language use in their daily life outside the classroom. Neither did they fully practice their language skills in class due to the excessive number of students in each class and the limited number of classroom sessions. They were also rarely offered outside classroom activities to promote 
their language proficiency. Learning behaviors mostly focused on regular class attendance and practicing language exercises. Not many of them reported the use of other learning resources for their self-study. Students showed the highest level of capability in their reading skills and the lowest level in their speaking and listening skills, indicating a need for much improvement in the latter two skills as was the case for their teachers. Most of the learners had a positive attitude toward foreign-language learning, but their attitudes toward English w as found to be less positive than that toward any other of the 1 anguages. The problems e ncountered by most learners were the lack of continuation in the language, the lack of sufficient time for practice, the unpleasantly warm and stuffy classrooms, and the noisy atmosphere. In addition, learning resources were too scarce, dull, and outdated to facilitate their language learning. Furthermore, most of the sample taken from the tertiary-education level reported that they did not feel wellequipped for further education and their future careers.

The data from the business-sector sample revealed that the foreign language used and needed most was English, followed by Mandarin and Malay respectively. However, the demand for personnel language competency in the specified foreign languages did not necessarily mean an increase in the number of positions to meet the demand but simply referred to the acquisition of additional languages by the existing personnel. The language skills required most were speaking and listening, and most employers showed little satisfaction with their personnel's language competency. Interesting evidence emerged when the employers were less satisfied with the language competency of language-degree holders than that of non-language-degree holders.

Suggestions from various groups in the sample included the establishment of local language centers for the service of language activities, the compilation of English, Mandarin, and Malay usage manuals published and distributed to those in relevant businesses, the integration of English learning into other subjects, the provision of language education in accordance with community needs, increased budget allocation for the employment of both native-speakers and Thai teachers, the enhancement of teachers' professional qualifications, the provision of learning resources and activities geared to foreign-language learning, and smaller class size, allowing learners more time for practice. 